\title{
Cerebral Metabolism in Severe Neonatal Hyperbilirubinemia
}

\author{
Floris Groenendaal, MD, PhD*; Jeroen van der Grond, PhD ; and Linda S. de Vries, MD, PhD*
}

\begin{abstract}
The metabolism of the basal ganglia was examined by using proton magnetic resonance spectroscopy in 5 neonates with severe hyperbilirubinemia. A decreased $\mathrm{N}$-acetylaspartate/choline ratio, indicating neuronal injury, and an abnormally high lactate $/ N$-acetylaspartate ratio were found only in the neonate with neonatal magnetic resonance imaging abnormalities and subsequent cerebral palsy. Pediatrics 2004;114:291-294; bilirubin, neonate, kernicterus, magnetic resonance spectroscopy, metabolism.
\end{abstract}

ABBREVIATIONS. MRI, magnetic resonance imaging; ${ }^{1} \mathrm{H}-\mathrm{MRS}$, proton magnetic resonance spectroscopy; NAA, $N$-acetylaspartate; Cho, choline; ABR, auditory brainstem response; AABR, automated auditory brainstem response; ADC, apparent diffusion coefficient; G6PD, glucose-6-phosphate dehydrogenase.

$\mathrm{E}$ levated levels of unconjugated bilirubin in neonates can induce changes in the mitochondria of the basal ganglia, resulting in a disturbed mitochondrial respiration, increased apoptosis, and so-called bilirubin encephalopathy. ${ }^{1,2}$ Animal experiments have indicated that disruption of the bloodbrain barrier, hypoxia, and acidosis contribute to bilirubin toxicity. ${ }^{3,4}$ Changes in the $N$-methyl-D-aspartate receptor of neurons may increase bilirubin toxicity. ${ }^{5}$ Tissue changes in the basal ganglia can be visualized by using magnetic resonance imaging (MRI) techniques. 6,7

For a decade cerebral metabolism of neonates has been studied by using proton magnetic resonance spectroscopy $\left({ }^{1} \mathrm{H}-\mathrm{MRS}\right) .{ }^{8}$ Reduced $N$-acetylaspartate (NAA)/choline (Cho) ratios and elevated lactate/ NAA ratios in asphyxiated term neonates predict an adverse neurodevelopmental outcome. ${ }^{8,9}$

In the present study we tested the hypothesis that alterations in cerebral metabolism could be demonstrated in vivo in neonates with high levels of unconjugated bilirubin.

\section{SUBJECTS}

Subjects were all 5 neonates admitted during the last 7 years to our level III neonatal intensive care unit with bilirubin levels of $\geq 25 \mathrm{mg} / \mathrm{dL}(\geq 425 \mu \mathrm{mol} / \mathrm{L})$. All neonates showed hypotonia on admission. Patient $\mathrm{E}$ had a definite abnormal clinical picture, with a high-pitched cry and opisthotonos. Additional clinical details

From the *Departments of Neonatology and $\ddagger$ Radiology, Wilhelmina Children's Hospital, University Medical Center Utrecht, Utrecht, Netherlands. Received for publication Sep 2, 2003; accepted Mar 3, 2004.

Address correspondence to: Floris Groenendaal, MD, PhD, Department of Neonatology, Wilhelmina Children's Hospital, University Medical Center Utrecht, Room KE 04.123.1, Lundlaan 6, 3508 AB Utrecht, Netherlands. E-mail: f.groenendaal@wkz.azu.nl

PEDIATRICS (ISSN 0031 4005). Copyright @ 2004 by the American Academy of Pediatrics. are presented in Table 1. A sixth neonate was excluded from the study because of propionic acidemia. MRI was performed for clinical reasons during the first week after birth. Informed consent was obtained to add ${ }^{1} \mathrm{H}$-MRS to the MRI examination. The study was approved by the Medical Ethical Committee of Wilhelmina Children's Hospital/University Medical Center Utrecht.

\section{METHODS}

Bilirubin was measured in capillary or arterial blood samples by using Vitros BuBc slides (Ortho-Clinical Diagnostics, Rochester, NY). The highest levels during the first week after birth are reported in Table 1. Albumin was within the normal range for all 5 neonates.

Auditory brainstem responses (ABRs) were obtained during the first week after birth until 1999; since 2000, the automated ABR (AABR) method followed by ABR was used. ${ }^{10}$ The aim of the ABR measurements was to find a threshold.

Follow-up of the patients was performed as described ${ }^{11}$ by using items from the examinations of Amiel-Tison, Touwen, and the Alberta Infant Motor Scale during the first year after birth, and Griffiths' tests were performed during the second year after birth. Cerebral palsy was graded according to the classification of Hagberg et al. ${ }^{12}$

\section{MRI/1'H-MRS}

Details of the methods have been reported elsewhere. ${ }^{11}$ Briefly, the examinations were performed in sedated neonates. Vacuum pillows (Med-Tec, Orange City, IA) were used to avoid movements of the patient's head while providing ear protection. Heart rates and transcutaneous oxygen saturation were monitored by using pulse oximetry (Nonin, Minneapolis, MN), and respiratory rates were monitored by using an abdominal transducer (Philips Gyroscan ACS-NT, Best, Netherlands).

\section{MRI}

Standard MRI was performed for localization of the volume of interest for ${ }^{1} \mathrm{H}-\mathrm{MRS}$ by using a 1.5-T Philips ACS-NT system. MRI included sagittal T1, axial turbo spin-echo T2, inversion recovery, and diffusion-weighted MRI. Apparent diffusion coefficient (ADC) of water images were created after diffusion-weighted MRI. ${ }^{13}$

\section{${ }^{1} \mathrm{H}-\mathrm{MRS}$}

For the ${ }^{1} \mathrm{H}-\mathrm{MRS}$ examination, a volume of interest of $\sim 3.5 \times 2.5$ $\times 2.0 \mathrm{~cm}^{3}$ was placed in the left basal ganglia, including the caudate nucleus, putamen, globus pallidus, and thalamus. A PRESS sequence with a repetition time of 2000 milliseconds was used. The echo time was 144 milliseconds, and 64 measurements were averaged. After zero-filling of the time-domain data points to 4096 data points, Gaussian multiplication of $5 \mathrm{~Hz}$, exponential multiplication of $-4 \mathrm{~Hz}$, Fourier transformation, and baseline correction were performed, NAA, (phospho-)creatine, and Cho peaks were identified at 2.02, 3.02, and $3.24 \mathrm{ppm}$, respectively. Lactate was measured as an inverted doublet at $1.33 \mathrm{ppm}$. Peak area ratios of NAA/Cho were calculated. Furthermore, the presence of a lactate peak was noted. Results were compared with normal values obtained in our institute. ${ }^{11}$

\section{RESULTS}

Results of MRI, ${ }^{1} \mathrm{H}-\mathrm{MRS}, \mathrm{ABR}$, and follow-up are shown in Table 2. 
TABLE 1. Patient Clinical Data

\begin{tabular}{|c|c|c|c|c|c|c|c|c|}
\hline Patient & Diagnosis & $\begin{array}{l}\text { Gestational } \\
\text { Age at } \\
\text { Birth, wk }\end{array}$ & $\begin{array}{c}\text { Age on } \\
\text { Admission, } \\
\text { d }\end{array}$ & $\begin{array}{l}\text { Birth Weight/ } \\
\text { Weight on } \\
\text { Admission, g }\end{array}$ & $\begin{array}{l}\text { Apgar } 1 \mathrm{~min} / \\
5 \mathrm{~min} \text { Score }\end{array}$ & $\begin{array}{l}\text { Age at Peak } \\
\text { Bilirubin, h }\end{array}$ & $\begin{array}{l}\text { Bilirubin Total/ } \\
\text { Conjugated, } \\
\text { mg/dL }\end{array}$ & $\begin{array}{c}\text { Albumin, } \\
\mathrm{g} / \mathrm{L}\end{array}$ \\
\hline A & Rhesus i & 38 & 0.5 & $3030 / 3030$ & $8 /$ & 24 & $29.2 / 1.5$ & 30.8 \\
\hline B & Cephalohematoma & 41.3 & 1 & $2350 / 2340$ & $8 / 9$ & 36 & $25.8 / 0.6$ & 20.3 \\
\hline $\mathrm{C}$ & $\mathrm{ABO}$ incompatibility & 39.3 & 4 & $3520 / 3240$ & $9 / 10$ & 77 & $47.5 / 0$ & 31.0 \\
\hline $\mathrm{D}$ & G6PD deficiency & 37.9 & 3 & $2915 / 2815$ & $9 / 10$ & 54 & $34.6 / 0$ & 30.5 \\
\hline $\mathrm{E}$ & G6PD deficiency & 38.7 & 4 & $3430 / 3185$ & $7 / 9$ & 81 & $41.8 / 0$ & 22.7 \\
\hline
\end{tabular}

\section{MRI and ${ }^{1} \mathrm{H}-\mathrm{MRS}$}

Abnormal neonatal MRI findings were seen only in the child who developed athetoid cerebral palsy (patient E; Fig $1 \mathrm{~A}$ and B). The bright signal in the globus pallidus (Fig 1A) is abnormal and cannot be seen in normal, term neonates. In addition, the posterior limb of the internal capsule does not show a high signal suggestive of myelination.

Diffusion-weighted MRI in this patient, however, did not show abnormalities. ${ }^{1} \mathrm{H}-\mathrm{MRS}$ showed the presence of lactate in 4 of the 5 neonates. Lactate/ NAA ratios were low $(<0.10)$ in patients $A, B, C$, and $\mathrm{D}$, which is within the normal range, but too high in patient E (0.20; Fig 1C). A low NAA/Cho ratio was demonstrated only in patient $\mathrm{E}$, who developed athetoid cerebral palsy. At present, none of the patients had a second MRI.

\section{ABR}

All 5 neonates showed signs of bilirubin toxicity, because the ABR was abnormal, ie, an increased threshold, in all 5. The ABR normalized in 3 neonates (A, B, and C) during the first 3 months after birth, improved in patient $\mathrm{D}$ at 4 months after birth, and remained definitely abnormal in patient $\mathrm{E}$. In patients $\mathrm{D}$ and $\mathrm{E}$, other causes of hearing loss were excluded.

\section{Neurodevelopment}

Three neonates (A, B, and C) were completely normal at follow-up at 24 months of age, and 1 (patient E) had severe athetoid cerebral palsy (recently examined at 12 months). Patient D showed truncal hypotonia and stereotyped movements at the age of 12 months.

\section{DISCUSSION}

In the present study, lactate resonances were demonstrated in the basal ganglia in 4 of the 5 term neonates with high bilirubin levels and abnormal brainstem auditory evoked responses. An abnor- mally high lactate resonance could be demonstrated only in patient E, who developed severe athetoid cerebral palsy. Serum lactate levels were measured only in patient $\mathrm{E}$, being $1.2 \mathrm{mmol} / \mathrm{L}$ on the day of the magnetic resonance examination. This cerebral lactate may have been the result of changes in mitochondrial function, leading to a decreased aerobic metabolism. ${ }^{2}$ Plasma base excess values in patients $\mathrm{A}, \mathrm{B}, \mathrm{C}$, and $\mathrm{D}$ at the time of ${ }^{1} \mathrm{H}-\mathrm{MRS}$ were within normal limits. Because ${ }^{1} \mathrm{H}-\mathrm{MRS}$ was not repeated, we do not know if brain lactate levels have normalized. Normal ${ }^{1} \mathrm{H}-\mathrm{MRS}$, including a small amount of lactate, has been described recently in a term neonate with severe hyperbilirubinemia and a normal follow-up examination at 12 months. ${ }^{14}$ The low NAA/ Cho ratio in neonate $\mathrm{E}$ indicates neuronal loss corresponding with abnormal MRI findings and cerebral palsy, because NAA is considered a neuronal marker. ${ }^{8}$ Disappearance of NAA within 24 to 48 hours after cerebral ischemia in adults has been reported. 15,16

No abnormalities were seen with diffusionweighted MRI, whereas definite changes were visible on T2- and inversion recovery-weighted images in patient $\mathrm{E}$. ADC values of the globus pallidus were $1.013 \times 10^{-3}$ (left) and $1.057 \times 10^{-3} \mathrm{~mm}^{2} /$ second (right), which we consider a normal value for a term neonate. ${ }^{17}$ In neonates with severe birth asphyxia, abnormalities can be detected by using diffusionweighted MRI during the first week after birth. ${ }^{13,18}$ Because the MRI was performed on patient $E$ on the 5th day after birth, very soon after the hyperbilirubinemia and exchange transfusion, we expected diffusion-weighted MRI abnormalities as the result of cell swelling induced by energy depletion. Recently, Rodrigues et $\mathrm{al}^{2}$ described bilirubin-induced apoptosis in isolated rat neurons. Changes in the mitochondrial membrane preceded cytochrome $c$ release and activation of the apoptosis cascade. Apoptotic cells are not swollen and are not likely to cause changes in diffusion-weighted MRI. In contrast, a disturbed en-

TABLE 2. MRI, MRS, ABR, and Follow-up

\begin{tabular}{clccll}
\hline Patient & \multicolumn{1}{c}{ MRI } & \multicolumn{2}{c}{ MRS } & & Follow-up \\
\hline & & NAA/Cho & Lac/NAA & & \\
A & Normal & 0.65 & 0.06 & Transient abnormalities & Normal \\
B & Normal & 0.60 & 0.09 & Transient abnormalities & Normal \\
C & Normal & 0.67 & 0.07 & Transient abnormalities & Normal \\
D & Normal & 0.62 & 0 & Transient abnormalities & Truncal hypotonia, stereotyped movements \\
E & Abnormal globus & $0.58^{*}$ & $0.20^{*}$ & Abnormal & Athetoid cerebral palsy \\
& pallidus & & & &
\end{tabular}

* NAA/Cho too low and lactate/NAA too high, according to reference values. ${ }^{11}$ 

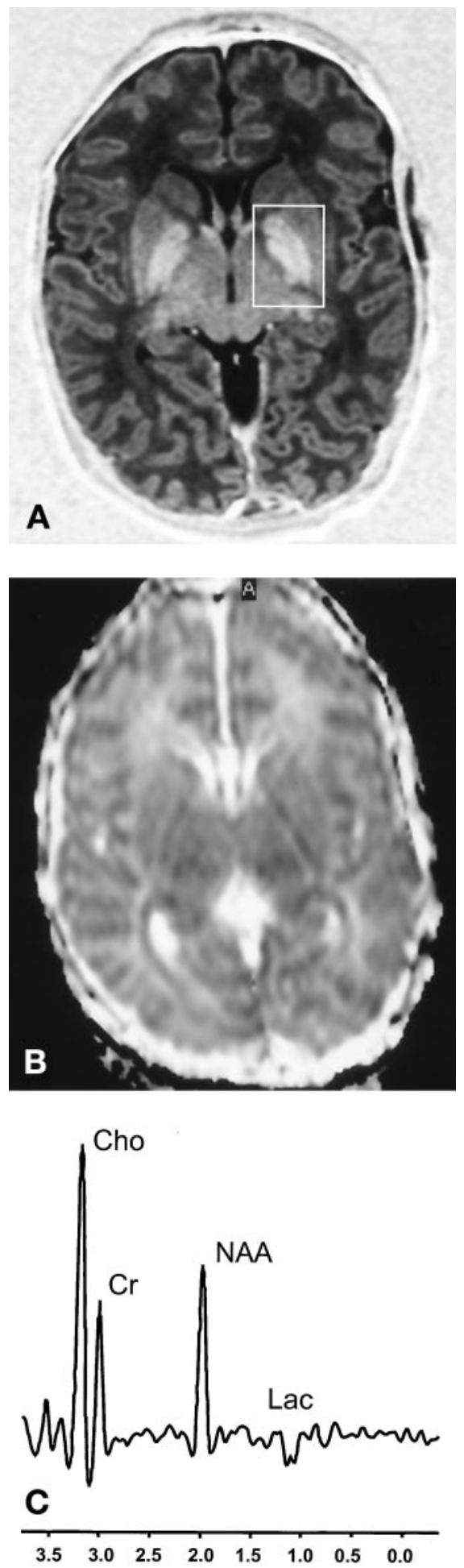

Fig 1. MRI and ${ }^{1} \mathrm{H}-\mathrm{MRS}$ of patient E. A, MRI (inversion recovery image) showing an abnormal, bright signal in the globus pallidus. The posterior limb of the internal capsule does not show high signal suggestive of myelination. The cortex and putamen, as well as the unmyelinated white matter, have a normal appearance. B, magnetic resonance image showing a map of the ADC of water. Areas of restricted diffusion of water should appear dark. In this image, no abnormalities of the ADC are noted. ADC values of the left and right globus pallidus were $1.013 \times 10^{-3}$ and $1.057 \times 10^{-3}$ $\mathrm{mm}^{2} /$ second, respectively. C, ${ }^{1} \mathrm{H}-\mathrm{MRS}$ of the left basal ganglia. NAA, Cho, (phospho-)creatine, and lactate resonances are indicated. Ratios of metabolites were calculated offline (see text for details). ergy production of the cell will lead to failing of membrane pumps and cell swelling with concomitant changes of diffusion-weighted MRI, as is the case in neonatal hypoxic-ischemic brain injury. ${ }^{13} \mathrm{Al}-$ tered neurotransmitter metabolism and changes in the $N$-methyl-D-aspartate receptor have been described in experiments focusing on bilirubin toxicity. ${ }^{5}$ These mechanisms may have played a role in the occurrence of seizures in patient E.

The normal appearance of diffusion-weighted MRI in patient $\mathrm{E}$ suggests that apoptosis caused by bilirubin might be more important than energy depletion and cell swelling in bilirubin encephalopathy. T1- and T2-weighted MRI abnormalities in the globus pallidus in patient $\mathrm{E}$ were obvious very early, ie, on the 5th day after birth. The posterior limb of the internal capsule did not appear normal. Because our patient was just $<40$ weeks' gestational age at the time of MRI, we do not consider this a sign of hypoxia-ischemia, as we do in neonates with a gestational age of 40 to 42 weeks. ${ }^{19}$ Both normal and abnormal appearances of the internal capsule have been described in neonates with kernicterus. ${ }^{20,21}$

It is of interest that the 2 infants with glucose-6phosphate dehydrogenase (G6PD) deficiency were affected most severely. The importance of G6PD deficiency in causing kernicterus has been stressed recently. ${ }^{22}$

In 4 neonates, the auditory abnormalities were transient. In 3 neonates (A, B, and C), the abnormalities normalized rapidly, and all 3 were normal at the age of 12 months. In patient $\mathrm{D}$, recovery of the ABR was much slower, and his neuromotor development is suspect at 12 months. Recently, Hansen and coworkers $^{23}$ described the spectrum of outcome in 3 neonates with severe hyperbilirubinemia: normal in one patient, hearing loss in another, and cerebral palsy with deafness in the third. Future studies are needed to demonstrate if MRI and ${ }^{1} \mathrm{H}-\mathrm{MRS}$ are better predictors of an adverse long-term outcome than clinical signs or ABR abnormalities persisting during the first week after birth in neonates with severe hyperbilirubinemia.

\section{CONCLUSIONS}

Changes in cerebral metabolism could be demonstrated in vivo in 1 neonate with severe hyperbilirubinemia using ${ }^{1} \mathrm{H}-\mathrm{MRS}$. These changes did not coincide with cell swelling, as demonstrated by using diffusion-weighted MRI.

\section{ACKNOWLEDGMENTS}

We thank the magnetic resonance technicians for their dedication and enthusiasm.

\section{REFERENCES}

1. Hansen TW. Mechanisms of bilirubin toxicity: clinical implications. Clin Perinatol. 2002;29:765-778

2. Rodrigues CM, Sola S, Brites D. Bilirubin induces apoptosis via the mitochondrial pathway in developing rat brain neurons. Hepatology. 2002;35:1186-1195

3. Ives NK, Bolas NM, Gardiner RM. The effects of bilirubin on brain energy metabolism during hyperosmolar opening of the blood-brain 
barrier: an in vivo study using 31P nuclear magnetic resonance spectroscopy. Pediatr Res. 1989;26:356-361

4. Ives NK, Cox DW, Gardiner RM, Bachelard HS. The effects of bilirubin on brain energy metabolism during normoxia and hypoxia: an in vitro study using 31P nuclear magnetic resonance spectroscopy. Pediatr Res. 1988;23:569-573

5. Hoffman DJ, Zanelli SA, Kubin J, Mishra OP, Delivoria-Papadopoulos $M$. The in vivo effect of bilirubin on the N-methyl-D-aspartate receptor / ion channel complex in the brains of newborn piglets. Pediatr Res. 1996;40:804-808

6. Martich-Kriss V, Kollias SS, Ball WS Jr. MR findings in kernicterus. AJNR Am J Neuroradiol. 1995;16:819-821

7. Yokochi K. Magnetic resonance imaging in children with kernicterus. Acta Paediatr. 1995;84:937-939

8. Groenendaal F, Veenhoven RH, van der Grond J, Jansen GH, Witkamp TD, de Vries LS. Cerebral lactate and $\mathrm{N}$-acetyl-aspartate/choline ratios in asphyxiated full-term neonates demonstrated in vivo using proton magnetic resonance spectroscopy. Pediatr Res. 1994;35:148-151

9. Robertson NJ, Cox IJ, Cowan FM, Counsell SJ, Azzopardi D, Edwards AD. Cerebral intracellular lactic alkalosis persisting months after neonatal encephalopathy measured by magnetic resonance spectroscopy. Pediatr Res. 1999;46:287-296

10. van Straaten HL, Hille ET, Kok JH, Verkerk PH; Dutch NICU Neonatal Hearing Screening Working Group. Implementation of a nation-wide automated auditory brainstem response hearing screening programme in neonatal intensive care units. Acta Paediatr. 2003;92:332-338

11. Roelants-van Rijn AM, van der Grond J, de Vries LS, Groenendaal F. Value of ${ }^{1} \mathrm{H}$-MRS using different echo times in neonates with cerebral hypoxia-ischemia. Pediatr Res. 2001;49:356-362

12. Hagberg B, Hagberg G, Olow I. The changing panorama of cerebral palsy in Sweden 1954-1970. II. Analysis of the various syndromes. Acta Paediatr Scand. 1975;64:193-200
13. Roelants-van Rijn AM, Nikkels PGJ, Groenendaal F, et al. Neonatal diffusion-weighted MR imaging: relation with histopathology or follow-up MR examination. Neuropediatrics. 2001;32:286-294

14. Patay Z, Robertson NJ, Cox IJ. Metabolic disorders in the neonate. In: Rutherford MA, ed. MRI of the Neonatal Brain. London, United Kingdom: W. B. Saunders; 2002:315-348

15. Gideon P, Henriksen O, Sperling B, et al. Early time course of Nacetylaspartate, creatine and phosphocreatine, and compounds containing choline in the brain after acute stroke. A proton magnetic resonance spectroscopy study. Stroke. 1992;23:1566-1572

16. Houkin K, Kamada K, Kamiyama H, Iwasaki Y, Abe H, Kashiwaba T. Longitudinal changes in proton magnetic resonance spectroscopy in cerebral infarction. Stroke. 1993;24:1316-1321

17. Neil JJ, Shiran SI, McKinstry RC, et al. Normal brain in human newborns: apparent diffusion coefficient and diffusion anisotropy measured by using diffusion tensor MR imaging. Radiology. 1998;209:57-66

18. Forbes KP, Pipe JG, Bird R. Neonatal hypoxic-ischemic encephalopathy: detection with diffusion-weighted MR imaging. AJNR Am J Neuroradiol. 2000;21:1490-1496

19. Rutherford MA, Pennock JM, Counsell SJ, et al. Abnormal magnetic resonance signal in the internal capsule predicts poor neurodevelopmental outcome in infants with hypoxic-ischemic encephalopathy. Pediatrics. 1998;102:323-328

20. Penn AA, Enzmann DR, Hahn JS, Stevenson DK. Kernicterus in a full term infant. Pediatrics. 1994;93:1003-1006

21. Harris MC, Bernbaum JC, Polin JR, Zimmerman R, Polin RA. Developmental follow-up of breastfed term and near-term infants with marked hyperbilirubinemia. Pediatrics. 2001;107:1075-1080

22. Johnson LH, Bhutani VK, Brown AK. System-based approach to management of neonatal jaundice and prevention of kernicterus. J Pediatr. 2002;140:396-403

23. Hankø E, Lindemann R, Hansen TWR. Spectrum of outcome in infants with extreme neonatal jaundice. Acta Paediatr. 2001;90:782-785 